\title{
Could there be any relationship between nutritional deficiencies and idiopathic chest pain in children?
}

\author{
Şeyma Kayalı, Nuran Belder²๑, Dilek Gürlek Gökçebay ${ }^{3} \odot$ \\ ${ }^{1}$ Department of Pediatric Cardiology, University of Health Sciences, Keçiören Training and Research Hospital, Ankara, Turkey \\ ${ }^{2}$ Department of Pediatrics, University of Health Sciences, Keçiören Training and Research Hospital, Ankara, Turkey, Turkey \\ ${ }^{3}$ Department of Pediatric Hematology and Oncology, University of Health Sciences, Keçiören Training and Research Hospital, Ankara, \\ Turkey
}

DOI: 10.18621 eurj.391401

\begin{abstract}
Objectives: Chest pain in childhood is a frequent cause of referral to pediatric cardiology departments although cardiac etiology is very rare. Etiology is usually unidentified and named as 'idiopatic chest pain'. It is also well known fact that chronic pain is associated with insuffiency of some nutritional factors even in childhood. Our aim was to investigate if there is a relationship between nutritional defiencies with idiopathic chest pain in children.

Methods: We retrospectively reviewed 364 patients who were referred pediatric cardiology department in one year period due to experienced chest pain more than one time. Among these patients, a total of 109 patients who had complete blood count, serum ferritin, vitamin B 12 and 25-(OH) vitamin D levels in pediatric outpatient clinics before and the etiology was still unidentified after a detailed cardiac and other examinations formed the study group. Age and sex matched 59 healthy children without chest pain formed the control group. All participants had been evaluated with a detailed physical examination and patients in chest pain group also had an electrocardiographic ve echocardiographic evaluation.

Results: Vitamin B12 and Vitamin D levels were lower in noncardiac chest pain group while there was no difference between groups in term of ferritin levels and complete blood count parameters. These difference is statistically significant particularly in vitamin D levels.

Conclusions: Our results showed that low Vitamin D levels is associated with chronic chest pain in children. The present study provide the necessity of evaluating nutritional parameters in children with noncardiac chest pain.
\end{abstract}

Keywords: Chest pain, children, ferritin, vitamin B12, vitamin D

Received: February 7, 2018; Accepted: June 22, 2018; Published Online: June 27, 2018

$\mathrm{E}$ ven in developed countries, nutritional deficiencies are worlwide common cause of anemia and various disorders [1-4]. In recent years, there are several studies that report the assosication between nutritional insuffiencies and diverse ilnesses,

chronic pain syndromes [4-6]. In particular, low vitamin $\mathrm{D}$ level has been linked to chronic pain and there is a growing body of literature about this subject in recent years. The possible underlying mechanism of relationship between chronic pain and vitamin D

Address for correspondence: Şeyma Kayall, MD., University of Health Sciences, Keçiören Training and Research Hospital, Department of Pediatric Cardiology, Pınarbaşı Mah., Sanatoryum Cad., Ardahan Sok., No:25, 06380 Keçiören, Ankara, Turkey

E-mail: ak-seyma@hotmail.com,Tel:+90(312) 35690 00,Fax:+90 (312) 3569002 
deficiency is that vitamin D has been found to act as a neuroactive steroid, interfere with the creation and role of neurotrophins, influence prostaglandin action, effect inflammatory pathways, and inhibit nitric oxide synthase and T-helper cells [7]. Studies reported that even mild vitamin $\mathrm{D}$ deficiency may produce a variety of musculoskeletal pains such as fibromyalgia-like pain, low back pain, and arthralgia [8]. However, many tissues express vitamin D receptors and like other hormones, vitamin $\mathrm{D}$ plays a role in a wide range of processes in the body and the relationship between vitamin $\mathrm{D}$ deficiency and different pain types such as nociceptive and inflamatuary pain has also been proven [9]. In addition to this, vitamin B12 has been regarded as painkilling vitamin for decades and has been used in the treatment of pain which is particularly neuropatic [10].

In respect of iron, iron status is an important risk factor for cardiovascular health and clinical spectrum of iron deficiency range from asymptomatic to heart failure [1] and analghesic effect of iron oxide particles in inflamatuary pain sydrome were showed in a recent mice study [11]. On the other hand, chest pain is one of the main causes of recurrent referral to pediatric emergency and pediatric cardiology departments and the most common etiology is still unknown and called as'idiopathic' with a percentage of 21-59 \% [12]. Different studies were made to enlight this unknown etiology to this date [13-16]. However, there has been no published studies that evaluated the relationship between idiopathic chest pain and nutritional deficiencies according to our knowledge.

The aim of this study was to contribute the management of children with chest pain by examining the serum levels of iron, vitamin B12 and vitamin D in these children and relationship between nutritional deficiencies and presence of idiopathic chest pain.

\section{METHODS}

The patients who were referred to pediatric cardiology because of recurrent chest pain between the dates of December 2016 to December 2017 were retrospectively reviewed. All participants with chest pain were screened with a detailed procedure including history, physical exam, electrocardiogram, transthorasic echocardiogram and were also evaluated for other possible causes of chest pain including gastroeusophageal reflux, costochondritis and pneumonia. A total of 109 patients who showed no evidence of obvious medical pathology and provided the condition of having complete blood count, serum ferritin, vitamin B12 and 25-(OH) vitamin D levels in pediatric outpatient clinics were considered eligible for the study group. Randomly chosen, age and sex matched healthy children without chest pain who was admitted pediatrics department for routine control formed the control group. Excluded from the study were any children with structural heart disease, hematologic disease (thalessemia, sicle cell anemia, etc.), dysrhythmia, chronic ilness or were taking any regular medications.

The serum levels of ferritin, vitamin B12 and 25$(\mathrm{OH})$ vitamin $\mathrm{D}$ was measured by chemiluminescent immunoassay method (Architect, Abbott, USA). Ferritin was lower than $25 \mathrm{ng} / \mathrm{ml}$ was considered as low iron storage [1]. Vitamin B12 deficiency was defined as serum level of vitamin B12 was $200 \mathrm{pg} / \mathrm{ml}$ [17]. Vitamin D insuffiency and vitamin D deficiency were considered when $25-(\mathrm{OH})$ vitamin D levels were level between 12-20 ng/ml and lower than $12 \mathrm{ng} / \mathrm{ml}$ respectively [18].

The present study was approved by a scientific committee comprising the hospital administration and the lecturers and performed in accordance with the Declaration of Helsinki.

\section{Statistical Analysis}

The data were recorded with the Statistical Package for the Social Sciences program version 21 (SPSS, Inc., Chicago, IL, USA). The distributions of continuous variables were analyzed with the ShapiroWilk test. The descriptive statistics were defined as mean \pm standard deviation for normally distributing data and as median (minimum-maximum) for nonnormally distributing data. The significance of the differences in mean values between two independent groups was analyzed with the Student t-test and the significance of the differences in median values between two independent groups was analyzed with the Mann-Whitney U test. Relationships between variables were tested with Pearson or Spearman correlation analysis where appropriate. A value of $p<$ 0.05 was taken to statistical significance. 
Table 1. Demogrophic and hematologic feaures of participants

\begin{tabular}{lccc}
\hline & $\begin{array}{c}\text { Study group } \\
(\mathbf{n}=\mathbf{1 0 9})\end{array}$ & $\begin{array}{c}\text { Control group } \\
(\mathbf{n}=\mathbf{5 9})\end{array}$ & $\boldsymbol{p}$ value \\
\hline Age (years) & $12.4 \pm 3.6$ & $11 \pm 4.6$ & 0.14 \\
$\mathrm{Gender}$ & $71(65.1 \%)$ & $30(50.8 \%)$ & 0.07 \\
$\mathrm{Hb}(\mathrm{g} / \mathrm{dl})$ & $13.8 \pm 1.37$ & $13.6 \pm 1.33$ & 0.13 \\
$\mathrm{Hct}(\%)$ & $41.4 \pm 5.3$ & $40.1 \pm 3.9$ & 0.08 \\
$\mathrm{RBC}\left(10^{6} / \mu \mathrm{L}\right)$ & $4882.7 \pm 367.6$ & $4880.6 \pm 377.2$ & 0.6 \\
Ferritin $(\mathrm{ng} / \mathrm{ml})$ & $36.1 \pm 42.7$ & $27.2 \pm 16.4$ & 0.5 \\
\hline Data are shown as mean \pm standard deviation or number $(\%) . \mathrm{Hb}=$ Hemoglobin, Hct $=$ Hematocrit, $\mathrm{RBC}=$ Red \\
blood cell count
\end{tabular}

\section{RESULTS}

A total of 364 children were admitted pediatric cardiology department due to recurrent chest pain in one year period. A total of 109 children who diagnosed with idiopathic chest pain had complete blood count, serum levels of ferritin, vitamin B12 and vitamin D in pediatric outpatient clinics and formed study group. The average age of study and control group was 12.4 \pm 3.6 years and $11 \pm 4.6$ years, respectively. There were $71(65.1 \%)$ girls in study group while there were $30(50.8 \%)$ girls in control group. There were no difference between groups in terms of age and gender ( $p=0.14$ and $p=0.07$, respectively) (Table 1$)$. There were no difference between groups in terms of serum ferritin levels and hemoglobin, hematocrit, red blood cell values $(p>0.05)$ (see Table 1$)$.

The serum vitamin B12 levels of study group was lower than control group although was not statistically significant $(p=0.1)$ (Table 2). There were $14(12.8 \%)$ children in study group with vitamin B12 deficiency while there were $8(13.6 \%)$ children vitamin B12 deficiency in control group.

Serum level of 25-(OH) vitamin D was significantly lower in study group $(\mathrm{p}=0.001)$. There were 65 (57.8\%) children with vitamin D insufficiency in study group while there were $18(30.5 \%)$ children with vitamin $\mathrm{D}$ insufficiency in control group. In addition to this, $40(36.7 \%)$ of children in study group had vitamin D deficiency and $3(5.1 \%)$ of children in control group had vitamin D deficiency $(p<0.01)$ (Table 2).

\section{DISCUSSION}

In this retrospective study we found that vitamin D level was significantly lower in children with idiopathic chest pain whereas there were no difference in terms of ferritin and vitamin B 12 levels.

The association of vitamin D deficiency with multiple forms of chronic pain are reported by several studies such as musculoscelatal, nociceptive, inflammatuary, cancer pain, etc.,[9, 19-24]. Although,

Table 2. Comparison of vitamin levels between groups

\begin{tabular}{lccc}
\hline & $\begin{array}{c}\text { Study group } \\
(\mathbf{n = 1 0 9 )}\end{array}$ & $\begin{array}{c}\text { Control group } \\
(\mathbf{n}=\mathbf{5 9})\end{array}$ & $\boldsymbol{p}$ value \\
\hline Vitamin B12 (pg/ml) & $326 \pm 125.7$ & $374.6 \pm 168$ & 0.1 \\
$25-(\mathrm{OH})$ Vitamin D (ng/ml) & $20.5 \pm 12.6$ & $26.6 \pm 14.4$ & $\mathbf{0 . 0 0 1}$ \\
Vitamin D deficieny & $40(36.7 \%)$ & $3(5.1 \%)$ & $<\mathbf{0 . 0 1}$ \\
Vitamin B12 deficiency & $14(12.8 \%)$ & $8(13.6 \%)$ & 0.9 \\
\hline
\end{tabular}

Data are shown as mean \pm standard deviation or number (\%). 
not yet fully elucidated, possible mechanism for vitamin $\mathrm{D}$ in pain management are the antiinflammatory effects mediated by reduced cytokine and prostaglandin release and effects on T-cell responses [7]. For this reason, vitamin D deficiency may lead to increased pain sensation, increased excitability and poor muscle function because of the lack of antiinflamatuary effect and its effect on nerve function $[8,9,21]$. Recent studies have been shown that vitamin $\mathrm{D}$ reduces pain severity, improves musculosceletal mobility [21-23]. Apart from vitamin D's effects on musculosceletal system it has been implicated that vitamin D supplementation is also useful to reduce headache with its neuroprotective effect even in pediatric age $[23,24]$.

In accordance with previous studies which evaluated vitamin D levels and different pain types, our study has showed that vitamin D levels are lower in children with idiopathic chest pain. Although the most common cause of chest pain in pediatric age is idiopathic chest pain, musculosceletal problems have also an important role in the etiology with a wide range of $12.8 \%-64 \%$ [24, 25]. Apart from the ilnesses like costocondritis, precordial catch syndrome etc., some musculosceletal problems may not have spesific anamnestic features or physical examination findings and may be diagnosed as idiopathic chest pain. Recent studies have been showed that vitamin D deficiency is related to growing pains and nonspesific musculosceletal pain in children [22, 28]. According to these findings, we defend that children with nonspesific musculosceletal pain as a result of the lack of vitamin D can also be presented as chest pain.

Vitamin B 12 is needed to make blood cells and to provide bone density. In addition to this, it is also a well known pain killing vitamin for decades [10]. However, underlying mechanism of its the analgesic effect is poorly understood. In case of vitamin B12 deficiency, neurologic dysfunction and chronic pain can be occured [5]. Vitamin B12 deficiency is mostly related with neuropathic chronic pain like diabetic neuropathies and different types of neuralgia [10]. In the present study, vitamin B12 levels were lower in chest pain group, however this difference were not statistically significant. The present result is also, because neuropathic pain is unexpected, etiology of chest pain in children.
There is very limited data about the relationship between iron status and pain. A recent animal study has been showed the analghesic effect of iron oxide particles in inflamatuary pain sydrome [11]. However, it is a well known fact that iron status is very important for cardiovascular health and clinical spectrum of iron deficiency range from asymptomatic to heart failure [1]. For this reason, ferritin levels also were evaluated in case of related any concealed cardiac problem that could cause chest pain. Our results did not show any relationship between chest pain and iron deficiency. In addition to this result, all patients had normal electrocardiographic and echocardiographic evalution.

\section{Limitations}

The present study has some limitations. As this was a single-center study, the number of cases was very small. Due to the retrospective nature of this study, follow-up information and the effect of vitamin deficiency treatment were not been collected. Although, only detailed history and electrocardiography is enough for excluding cardiac etiology in children with chest pain, echocardiographic examination was performed because of forming the study group from the cases evaluated at pediatric emergency and/or other departments before and referred to pediatric cardiology department. Further studies should be performed with a larger number of subjects.

\section{CONCLUSION}

Children are not small size of adults and have a growing and developing nature. During this growing period, musculusceletal health which vitamin $\mathrm{D}$ is a major component is very important. Our study showed that low vitamin D levels are associated with idiopathic chest pain in children. We believe that most idiopathic chest pain cases may have nonspesific musculosceletal pain and measuring vitamin D levels provides to diagnose and avoid unnecessary further cardiac and other unnecessary medical testing .This study emphasized the necessity of evaluating nutritional parameters especially vitamin D levels in children with idiopathic chest pain. 


\section{Authors' contribution}

$\mathrm{SK}=$ Study design, statistical analysis, manuscript writing, NB = Study design, data collection, DGG = Study design, review of manuscript.

\section{Conflict of interest}

The authors disclosed no conflict of interest during the preparation or publication of this manuscript.

\section{Financing}

The authors disclosed that they did not receive any grant during conduction or writing of this study.

\section{REFERENCES}

$\mathrm{T}$, et al. Low iron stores in otherwise healthy children affect electrocardiographic markers of important cardiac events. Pediatr Cardiol 2017;38:909-14.

[2] Stoltzfus RJ. Iron deficiency: global prevalence and consequences. Food Nutr Bull 2003;24(4 Suppl):99-103.

[3] Ghishan FK, Kiela PR. Vitamins and minerals in inflammatory bowel disease. Gastroenterol Clin N Am 2017;46:797-808.

[4] Koduah P, Paul F, Dörr JM. Vitamin D in theprevention, predictionand treatment of neurodegenerative and neuroinflammatory diseases. EPMA J 2017;8:313-25.

[5] Tick H. Nutrition and pain. Phys Med Rehabil Clin N Am 2015;26:309-20.

[6] Straube S, Moore AR, Derry S, Mc Quay HJ. Vitamin D and chronic pain. Pain 2009;141:10-3.

[7] Shipton EA, Shipton EE. Vitamin D and pain: Vitamin D and its role in the etiology and maintenance of chronic pain states and associated comorbidities. Pain Res Treat 2015;2015:904967.

[8] Abbasi M, Hashemipour S, Hajmanuchehri F, Kazemifar AM. Is vitamin D deficiency associated with non specific musculoskeletal pain? Glob J Health Sci 2012;5:107-11.

[9] Helde-Frankling M, Björkhem-Bergman L. Vitamin D in pain management. Int J Mol Sci 2017;18. pii:E2170.

[10] Park MJ, Lee J, Lee JK, Joo SY. Prevalence of vitamin D deficiency in Korean children presenting with nonspecific lower-extremity pain. Yonsei Med J 2015;56:1384-8.

[11] Zhang M, Han W, Hu S, Xu H. Methylcobalamin: a potential vitamin of pain killer. Neural Plast 2013;2013:424651.

[12] Wu PC, Hsiao HT, Lin YC, Shieh DB, Liu YC. The analgesia efficiency of ultrasmall magnetic iron oxide nanoparticles in mice chronic inflammatory pain model. Nanomedicine 2017;13:1975-81.

[13] Chun JH, Kim TH, Han MY, Kim NY, Yoon KL. Analysis of clinical characteristics and causes of chest pain in children and adolescents. Korean J Pediatr 2015;58:440-5.

[14] Eslick GD, Jones MP, Talley NJ. Non-cardiac chest pain: prevalence, risk factors, impact and consulting - a population-based study. Aliment Pharmacol Ther 2003;17:1115-24.

[15] Friedman KG, Kane DA, Rathod RH, Renaud A, Farias M, Geggel $\mathrm{R}$, et al. Management of pediatric chest pain using a standardized assessment and management plan. Pediatrics 2011;128:239-45.

[16] Evangelista JA, Parsons M, Renneburg AK. Chest pain in children: diagnosis through history and physical examination. J Pediatr Health Care 2000;14:3-8.

[17] Hvas AM, Nexo E. Diagnosis and treatment of vitamin B12 deficiency--an update. Haematologica 2006;91:1506-12.

[18] Munns CF, Shaw N, Kiely M, Specker BL, Thacher TD, Ozono K, et al. Global Consensus Recommendations on Prevention and Management of Nutritional Rickets. J Clin Endocrinol Metab 2016;101:394-415.

[19] Zadro J, Shirley D, Ferreira M, Carvalho-Silva AP, Lamb SE, Cooper $\mathrm{C}$, et al. Mapping the association between vitamin $\mathrm{D}$ and low back pain: a systematic review and meta-analysis of observational studies. Pain Physician 2017;20:611-40.

[20] Heuch I, Heuch I, Hagen K, Mai XM, Langhammer A, Zwart JA. Is there an association between vitamin $\mathrm{D}$ status and risk of chronic low back pain? A nested case-control analysis in the Nord-Trøndelag Health Study. BMJ Open 2017;7:e018521.

[21] Plotnikoff GA, Quigley JM. Prevalence of severe hypovitaminosis $\mathrm{D}$ in patients with persistent, nonspecific musculo skeletal pain. Mayo Clin Proc 2003;78:1463-70.

[22] Blagojevic Z, Nikolic V, Kisic-Tepavcevic D, Terzic Supic Z, Kovacevic R, Zivkovic Z, et al. Musculoskeletal pain and vitamin D defciency in children: a pilot follow-up study of vitamin D therapy in musculoskeletal/orthopedic conditions. Acta Chir Orthop Traumatol Cech 2016;83:21-6.

[23] Ward KA, Das G, Berry JL, Roberts SA, Rawer R, Adams JE, et al. Vitamin D status and muscle function in post-menarchal adolescent girls. J Clin Endocrinol Metab 2009;94:559-63.

[24] Cayir A, Turan MI, Tan H. Effect of Vitamin D therapy in addition to amitriptyline on migraine attacks in pediatric patients. Braz J Med Biol Res. 2014;47:349-54.

[25] Lawrence DW, Sharma B. A review of the neuroprotective role of vitamin $\mathrm{D}$ in traumatic brain injury with implications supplementation post-concussion. Brain Inj 2016;30:960-8.

[26] Massin MM, Bourguignont A, Coremans C, Comté L, Lepage P, Gérard P. Chest pain in pediatric patients presenting to an emergency department or to a cardiac clinic. Clin Pediatr (Phila) 2004;43:231-8.

[27] Hambrook JT, Kimball TR, Khoury P, Cnota J. Disparities exist in the Emergency Department evaluation of pediatric chest pain. Congenit Heart Dis 2010;5:285-91.

[28] Qamar S, Akbani S, Shamim S, Khan G. Vitamin D levels in children with growing pains. J Coll Physicians Surg Pak 2011;21:2847. 